\title{
Determinants of Investments in Energy Sector in Poland
}

\author{
Robert Lisowski $^{1}{ }^{\mathbb{D}}$, Maciej Woźniak ${ }^{1, * \mathbb{D}}$, Paweł Jastrzębski ${ }^{1} \mathbb{D}$, Simeon Karafolas ${ }^{2}$ and Marek Matejun $^{3} \mathbb{D}$ \\ 1 AGH University of Science and Technology, 30-059 Kraków, Poland; rlisowsk@zarz.agh.edu.pl (R.L.); \\ pjastrze@agh.edu.pl (P.J.) \\ 2 Department of Accounting and Finance, University of Western Macedonia, 50100 Kozani, Greece; \\ skarafolas@uowm.gr \\ 3 Faculty of Management, University of Lodz, 90-137 Łódź, Poland; marek.matejun@uni.lodz.pl \\ * Correspondence: mwozniak@zarz.agh.edu.pl
}

check for updates

Citation: Lisowski, R.; Woźniak, M.; Jastrzębski, P.; Karafolas, S.; Matejun, M. Determinants of Investments in Energy Sector in Poland. Energies 2021, 14, 4526. https://doi.org/ $10.3390 /$ en 14154526

Academic Editors: Luigi Aldieri and Sergey Zhironkin

Received: 20 June 2021

Accepted: 20 July 2021

Published: 27 July 2021

Publisher's Note: MDPI stays neutral with regard to jurisdictional claims in published maps and institutional affiliations.

Copyright: (c) 2021 by the authors. Licensee MDPI, Basel, Switzerland. This article is an open access article distributed under the terms and conditions of the Creative Commons Attribution (CC BY) license (https:// creativecommons.org/licenses/by/ $4.0 /)$.

\begin{abstract}
There is much research about the determinants of investments, but there is a shortage of similar studies for Poland. Therefore, the overall goal of the paper is to analyze the determinants of investments made by enterprises from the energy sector as well as their delays in Poland in the years 2000-2019. In this period, a strong growth of investments in energy was observed in the country. In connection to this, the authors set four hypotheses and verified them with the following statistical methods: canonical analysis, linear and causality correlation, autocorrelation and cointegration tests. The paper found that there is a relationship between public consumption and investment spending of small enterprises in Poland. That means that only some macroeconomic parameters are connected with investments. Moreover, the changes in the value of past investments has a negative influence in current investments.
\end{abstract}

Keywords: energy sector; investments; macroeconomic indicators; GDP; interest rates; Poland

\section{Introduction}

The energy sector is crucial as a source of national income in many countries. The availability of different energy sources is essential for the world economy. Moreover, modern economies cannot be sustained without those sources. This is confirmed by data presented in Figure 1 [1].

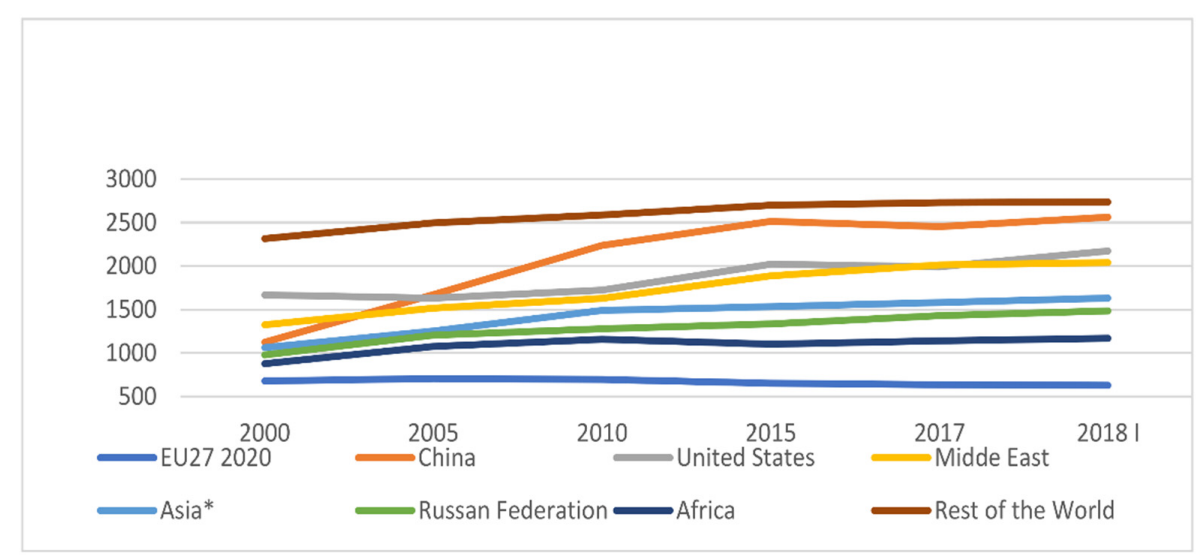

Figure 1. World Energy Production by Region in Mtoe. Source: EU energy in figures Statistical Pocketbook 2019.

Economic growth and energy demand are interlinked [2]. As the economy grows, the demand for energy increases, and if there is a reduction in energy production it means an decrease of Gross Domestic Product (GDP)—see Figure 2 [3]. It is, therefore, important to know the relationship between energy investment and key macroeconomic 
indicators, especially as investment decisions are strongly influenced by the socio-economic environment [4].

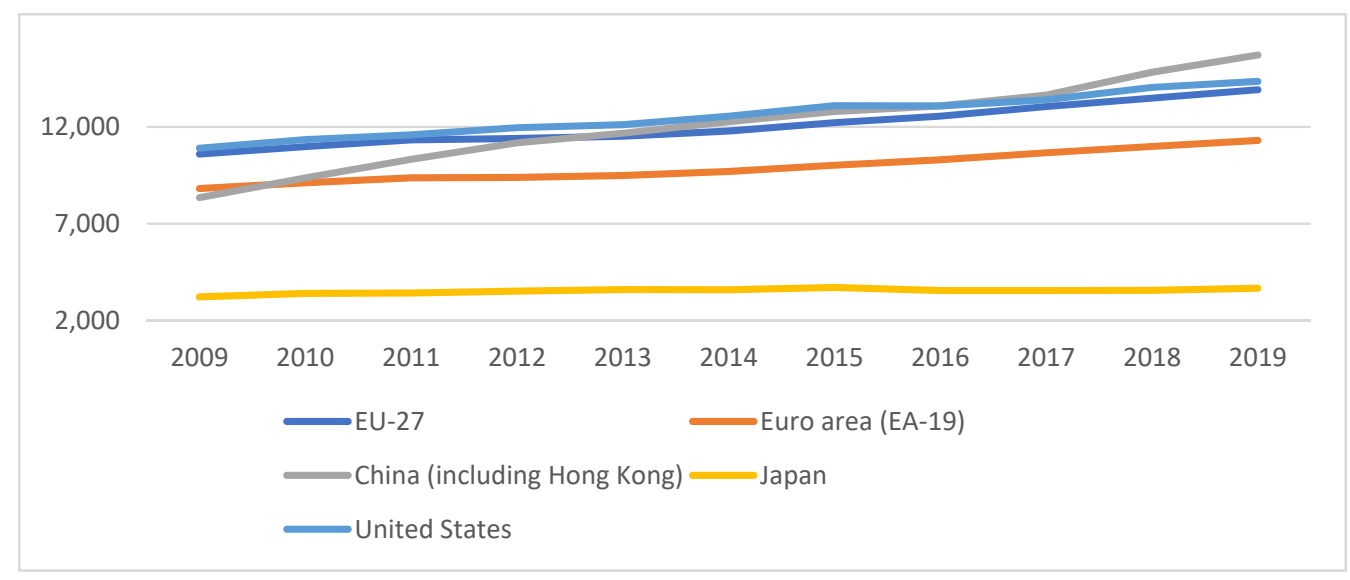

Figure 2. GDP at current market prices [billion PPS], 2009-2019. Source: Eurostat (online data code: prc_ppp_ind).

The relationship of energy and economic growth has been the object of several studies. The conclusion was the positive influence of renewable energy on economic growth and in particular the biomass energy in EU-28 [5] and renewable energy consumption on GDP [6]. A bidirectional causality between economic growth and renewable energy consumption was found in the case of 34 Sub-Saharan emerging countries [7] as well as in the case of 26 European countries [8]. Grijo and Soares [9], examining the example of solar photovoltaic investments in 18 European countries, found a positive impact on the economic growth that is more evident in some countries, such as France, Germany, Italy and the UK. It is worth mentioning that the investments of the member states of the European Union in renewable energy production also has an impact in SMEs [10].

Investments are one of the crucial elements of the post-pandemic recovery. However, they can be determined by several factors, internal or external to the company as macroeconomic ones. In the second case, the current economic situation and the expected growth rate of real GDP in the future may influence planned investments. Existing production capacity and interest rates may have a negative impact [11]. Financial constraints, either due to bank lending or own sources available for investments, also may have a crucial effect on investments [12,13]. Moreover, an economic crisis can have a determinant role on investments, as indicated in several studies related to the crisis of 2008-2009. Akbar et al. [14], based on UK companies in 2007-2009, concluded that credit constraints can postpone firms' decision to invest. Companies prefer increasing their cash reserves and cutting investments in a crisis period. Banking constraints are additional determinants for SMEs and young enterprises as concluded by Balduzzi et al. [15] in the case of Italy. Similar conclusions are reported in the case of The Netherlands [13], Belgium [16] and Portugal [17]. Perić and Đurkin [18], in the case of Croatia, concluded that the decisions of firms were motivated mostly by how they could survive the crisis, preferring to replace worn-out assets. Investments related to innovation may be affected more than other investments $[19,20]$. Archibugi et al. [21] found, on the contrary, that this is not true in all cases They noticed that new entrants and small enterprises can grow investments with innovation. The negative economic conjuncture and psychology may have a more determinant role on the decision of investments compared to the costs, as concluded by Karafolas and Ragias. In the Greek case, investments are not realized although publicly funded [22].

All these cases regard other countries. Moreover, these studies include various sectors. However, in the global situation, climate change also has a significant impact on the development of national energy strategies and, consequently, on their economic systems. It includes also the Polish Energy Policy until 2040, PEP 2040 [23]. The energy policy 
assumptions are linked to investment in the energy sector. Furthermore, the impact of investment decisions are long-term and have a strong impact on the environment, the economy and socio-political conditions. The challenge is the attempt to realize the targets set for 2020, which set the path for the energy transition.

In 2009, Figure 3, a regulatory package was implemented by the European Union (EU). It included three main targets for tackling climate change by 2020 (the so-called $3 \times 20$ package). The Member States have to participate according to their capabilities. Poland is obliged to:

- Increase energy efficiency by saving primary energy consumption by 13.6 Mtoe between 2010 and 2020 compared to the 2007 fuel and energy demand forecast;

- Increase the share of RES energy in gross final energy consumption to $15 \%$ by 2020 ;

- Reduce greenhouse gas emissions by 20\% (compared to 1990) until 2020 (2005 levels: $-21 \%$ in EU ETS and $-10 \%$ non-ETS sectors).

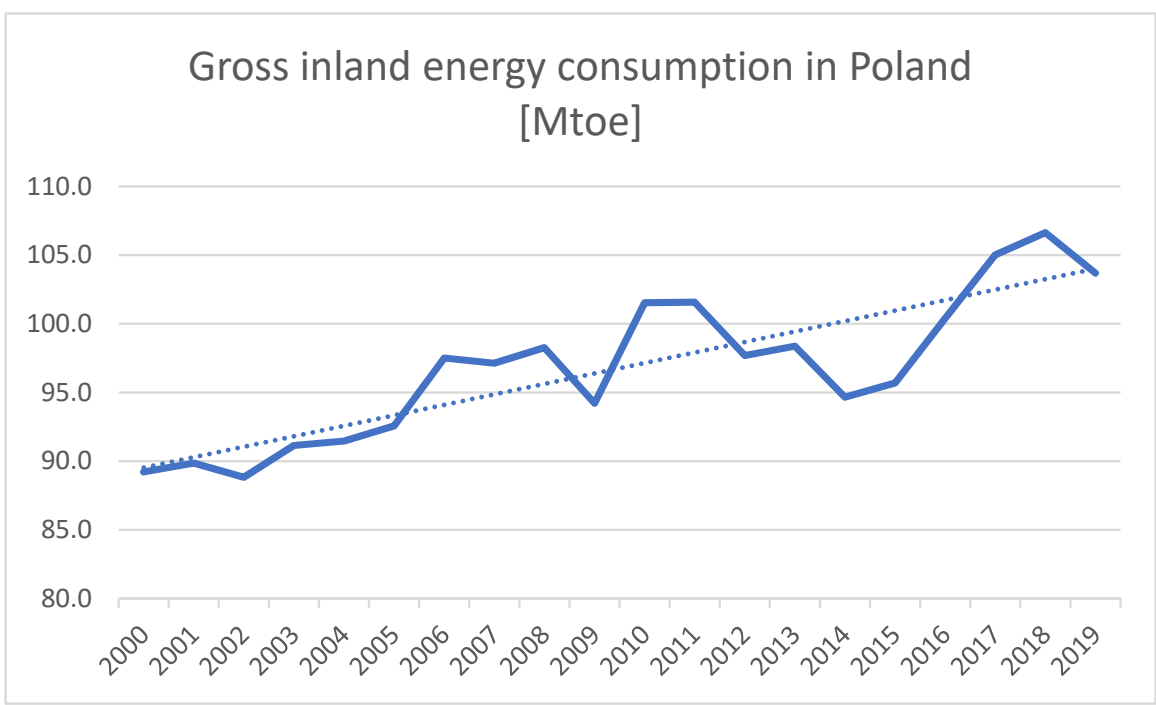

Figure 3. Gross inland consumption in Poland [Mtoe]. Source: Authors' elaboration based on EU energy figures in Statistical Pocketbook 2019.

Therefore, The Polish Energy Policy 2040 is based on three pillars:

- Fair energy transition;

- A zero-emission energy system;

- Good air quality.

These defined pillars force significant financial investments in the transition in the next years-modernization of the energy system in the country, and increases in the level of investment in fixed assets in energy companies.

The directions of investment expenditure have been described with specific objectives that focus, on the one hand, on the optimal use of energy resources, coal and lignite, and on the other hand, on the development of renewable energy sources or improving energy efficiency [21]. An important issue of energy efficiency regards the development electricity generation and grid infrastructure. The power balance must ensure the stability of energy supply and the flexibility of the electricity system as well as the implementation of international obligations. Furthermore, it needs to be connected with changes in the energy market and global trends. It is worth mentioning that only efficient and sufficiently developed infrastructure will ensure security of the energy supply [22]. The expansion of generation and grid infrastructure is going to create an almost new electricity system by 2040 .To a significant extent it will be based on zero-emission sources. These measures will have an impact on the economy as a whole, for instance direct investment, the labor market or GDP [23]. 
As mentioned earlier, investments in the energy sector are characterized by high expenditures for capital goods. Moreover, they may have a long-term impact on the economy through influence on the labor market, raw materials, the environment, etc. On the other hand, the preparation of investment plans in the energy sector cannot be done without an analysis of historical data as well as forecasts concerning, for example, energy production and consumption (Figure 4), as well as data on macroeconomic indicators such as GDP, employment level or cost [24] of external funds, particularly interest rates on loans.

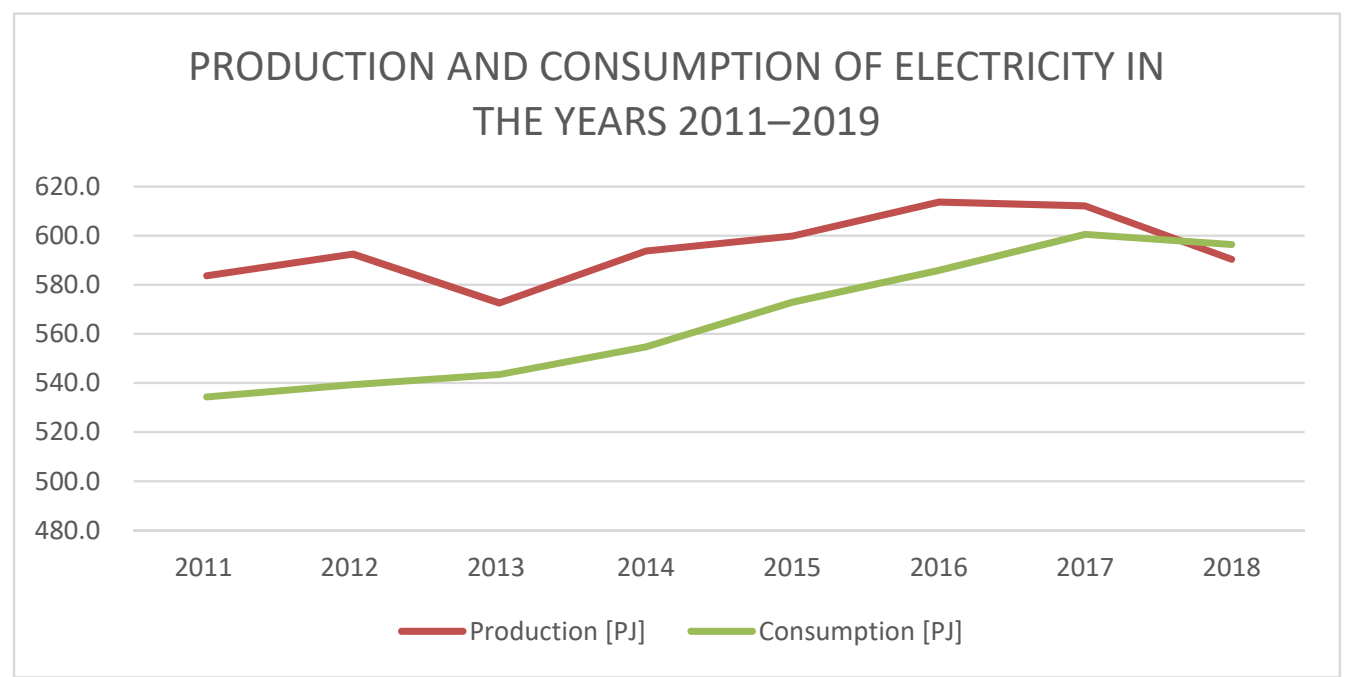

Figure 4. Production and consumption of electricity in Poland: 2011-2019. Source: Główny Urząd Statystyczny.

Understanding the relationship between these economic indicators and factors affecting the level of investment in the energy sector will help to plan future actions, particularly in the context of spending on investments from funds intended for the energy transition.

There is a shortage of advanced research for Poland connected with these problems. In connection with the research gaps, the overall goal of the paper is to analyze the determinants of investments made by enterprises from the energy sector as well as their delays in Poland in the years 2000-2019. To this aim, the paper examines four parameters that can have an influence on the investments in energy in the case of Poland: past investments of the sector, macroeconomic parameters, consumption and interest rates. For this purpose we collected data for the years 2000-2019 and grouped in five groups: total investments, investments of non-financial enterprises from the energy sector, macroeconomic indicators for the energy sector, household consumption and interest rates of loans to non-financial enterprises.

This is the first study, to our knowledge, discussing the influence of these macroeconomic parameters on the determinants of investments in Poland. The results of our investigation present further directions of research since the discussion of investments in renewable energy is also linked to the replacement of energy sources in Poland, based until now on the extraction of lignite or coal. The findings may be compared to other countries using similar source energies so far. The paper is organized as follows: after the introduction with a brief review of literature, Section 2 presents the hypotheses development. Then, we explain the methodology. Section 4 presents the collected data and the results of the statistical analysis and is followed by Section 5 with Discussion and Conclusions.

\section{Hypotheses Development}

In connection to the research gaps and taking into consideration the aim of the paper, the authors decided to set a few hypotheses. According to the macroeconomics theory, there are some factors that should have an impact on investments of enterprises: production, 
consumption, interest rates and capacity of companies, which is connected with past investments.

The neoclassical growth models find investments are the most important factor for economic growth [25]. The research of Inessa et al. [26] for Poland in the years 20052017 reveals that real GDP growth has the highest influence on the investment potential of enterprises. Woźniak et al. [27] analyzed the impact of macroeconomic factors on investments in Poland in the years 2005-2018. They concluded there is a relationship between these indicators in the case of domestic demand, gross accumulation and Gross National Product. However, Granger causality confirmed the impact of macroeconomic factors but only for small companies. Nevertheless, these findings concern all sectors of the economy.

In connection to the above, we set the first hypothesis:

Hypothesis 1 (H1). Changes in the value of macroeconomic indicators have a positive impact on changes in investment spending by companies from the energy sector in Poland.

Investments of enterprises lead to increase in the supply. According to the market theory, quantity supplied should meet quantity demanded. In the case of the energy sector, the latter is connected with both public consumption and consumption of households. Therefore, we set the second hypothesis:

Hypothesis $\mathbf{2}$ (H2). Changes in the value of consumption have a positive impact on changes in investment spending by companies from the energy sector in Poland.

According to the economic theory, the return on investment (RoI) must be higher than the cost of funds. It does not matter whether a firm uses a loan or equity, because in the latter case there is an opportunity cost of capital. Therefore, with higher interest rates, more projects with lower RoI are rejected. In connection to the above, we set the third hypothesis:

Hypothesis 3 (H3). Changes in the value of interest rates have a negative impact on changes in investment spending by companies from the energy sector in Poland.

The planned investments depend negatively, among others, on existing production capacity [11]. This is connected with investments of enterprises in the past. Woźniak et al. [27] reveal that past investments have a negative influence on investments of enterprises in Poland. However, there is one exception-small companies. This research concerns all sectors of the economy. Therefore, the fourth hypothesis is based on the negative relationship with the existing production capacity.

Hypothesis 4 (H4). Changes in the value of past investments have a negative impact on changes in current investment spending by companies from the energy sector in Poland.

In order to verify these hypotheses, we decided to use statistical analyses.

\section{Methodology}

\subsection{Canonical Analysis}

Canonical analysis is a procedure for estimating, in particular, the relationship between two sets of variables. The method creates the canonical variables, which are weighted sums of input s from a given set. A pair of canonical variables from both sets is called the canonical root.

The method selects weights in these sums-the canonical weights-in order to maximize the correlation between the first pair from both sets, then the second pair and so forth. The maximum number of roots is equal to the minimum of the number of inputs in both sets. Canonical variables for the same set are uncorrelated. 
Converting the inputs to canonical variables corresponds to the introduction of a new coordinate system, with not necessarily perpendicular axes and scales other than the original. Then, canonical correlation looks for a way of presenting two data sets in which the similarities between them are most visible.

The basic model of canonical correlation is as follows:

$$
\begin{aligned}
& \mathrm{U}=\mathrm{A}^{\mathrm{T}} \mathrm{X} \\
& \mathrm{V}=\mathrm{B}^{\mathrm{T}} \mathrm{Y}
\end{aligned}
$$

where:

$\mathrm{X}, \mathrm{Y}$-matrices in which each column corresponds to one of the input variables from the first $(X)$ and second $(Y)$ set;

A, B-determined vectors of coefficients;

$\mathrm{U}, \mathrm{V}$-canonical variables whose correlation is maximized.

The squares of the correlation coefficients between successive pairs of canonical variables are eigenvalues that can be interpreted as a proportion of the variance explained by individual canonical roots.

It is usually assumed that canonical variables represent some kind of hidden, directly unobservable variables. Therefore, the results of the analysis require often to find an interpretation of these variables in the real world $[28,29]$.

\subsection{Linear and Causality Correlations}

3.2.1. Test of Kwiatkowski, Philips, Schmidt and Shin

This is aimed to check the stationarity of the series. There are two hypotheses:

Hypothesis $\mathbf{0}$ (H0). The time series are stationary, H1: The time series are non-stationary.

The KPSS test has a complex form and a very complicated probability distribution. The variable is stationary if the following terms are met:

- The expected value (mean value) is steady and neutral in time;

- The variance is steady and neutral in time;

- The covariance among different variables depends only on the case numbers and is autonomous of time.

Classic examples of non-stationary variables are macroeconomic ones. We regularly see a trend for these variables, which indicates that the expected value is fluctuating. The linear model made for such variables may seem accurate, which could be verified by its confirmation. In fact, it can be the apparent regression, and this phenomenon was described by Granger $[27,30]$. One often can transform a sequence of observations to a stationary series by calculating the differences. The KPSS test is built on linear regression. It splits a series into three parts: a deterministic trend, a random walk, and a stationary error. If the variable is stationary, it will have a stable factor for an interceptor and the series will be stationary near a fixed level $[27,31]$. The analysis uses ordinary least squares find the equation, which differs slightly depending on whether one need to test for level stationarity or trend stationarity [32]. A basic version, not including the time trend factor, is used to test level stationarity.

The null and alternative hypotheses go after the reverse system of the Dickey-Fuller test. The structure of the KPSS test is as follows:

$$
\begin{gathered}
y_{t}=r_{t}+\xi_{t}+\varepsilon_{t} \\
r_{t}=r_{t-1}+u_{t}
\end{gathered}
$$

where $\varepsilon_{\mathrm{t}}$ is the stationary random term.

If the variance of the random term $u_{t}$ is equal to zero, then the values of $r_{t}=r_{0}$ are constant for every $t$. Then, the process $\mathrm{y}_{\mathrm{t}}$ is the sum of the constant $\mathrm{r}_{0}$ or the constant and 
the deterministic tendency $r_{0}+\xi_{t}$ and the stationary purely random component. If the variance of the random term in the second equation is different from zero, this equation determines the accidental walk process. Then, the $y_{t}$ process is the amount of the $r_{t}$ process and possibly the deterministic trend $\xi_{t}$ and the purely accidental stationary factor. Therefore it is non-stationary $[27,28,33]$.

\subsubsection{Pearson's Linear Correlation Coefficient}

The overall correlation coefficient for a completed-unordered-series of two discrete or continuous variables is computed as follows:

$$
r_{x y}=\frac{\frac{1}{n} \cdot \sum_{i=1}^{n}\left(x_{i}-m_{x}\right) \cdot\left(y_{i}-m_{y}\right)}{s_{x} \cdot s_{y}}
$$

where the numerator is named covariance, $\mathrm{s}_{\mathrm{x}}, \mathrm{s}_{\mathrm{y}}$ are the standard deviations of the variables $\mathrm{X}$ and $\mathrm{Y}, \mathrm{m}_{\mathrm{x}}$ and $\mathrm{m}_{\mathrm{y}}$ are their mathematics means, and $\mathrm{n}$-amount of pairs of informationstatistical units.

\subsubsection{Test of Granger}

Granger causality declares that the variable $Y$ is the cause of the variable $X$, if the present values of the variable $Y$ can be forecast with higher accuracy using the past $X$ values rather than without their use [31,32]: The Granger causality analysis is based on the estimation of the following models [31]:

$$
\begin{gathered}
\mathrm{y}_{\mathrm{t}}=\alpha_{1} \mathrm{y}_{\mathrm{t}-1}+\alpha_{2} \mathrm{y}_{\mathrm{t}-2}+\ldots+\alpha_{\mathrm{k}} \mathrm{y}_{\mathrm{t}-\mathrm{k}}+\varepsilon_{\mathrm{t}} \\
\mathrm{y}_{\mathrm{t}}=\alpha_{1} \mathrm{y}_{\mathrm{t}-1}+\alpha_{2} \mathrm{y}_{\mathrm{t}-2}+\ldots+\alpha_{\mathrm{k}} \mathrm{y}_{\mathrm{t}-\mathrm{k}}+\beta_{1} \mathrm{x}_{\mathrm{t}-1}+\beta_{2} \mathrm{x}_{\mathrm{t}-2}+\ldots+\beta_{\mathrm{k}} \mathrm{x}_{\mathrm{t}-\mathrm{k}}+\eta_{\mathrm{t}}
\end{gathered}
$$

where $y_{t}$ is implementation of the $Y$ process, $x_{t}$ is implementation of the $X$ process, $\alpha_{1}$, $\beta_{1}$ are parameters of a model, $\mathrm{k}$ is the lag of a model, $\varepsilon_{t}$ is an accidental factor of the $Y_{t}$ model explained only by its own delayed values and $\eta_{t}$ is a random factor of the $Y_{t}$ model explained only by its own delayed $X_{t}$ values. Granger causality checks the null hypothesis that there are no significant differences between the residual variances of the model that implies no causality:

$$
\mathrm{H}_{0}: \sigma^{2}\left(\varepsilon_{\mathrm{t}}\right)=\sigma^{2}\left(\eta_{\mathrm{t}}\right)
$$

In the view of the alternative hypothesis:

$$
\mathrm{H}_{1}: \sigma^{2}\left(\varepsilon_{\mathrm{t}}\right) \neq \sigma^{2}\left(\eta_{\mathrm{t}}\right)
$$

where $\sigma^{2}\left(\varepsilon_{t}\right), \sigma^{2}\left(\eta_{t}\right)$ are the variances of the random component of the models.

Furthermore, the choice of the delay order for a specific model was constructed on the criteria of AIC (Akaike criterion), BIC (Schwartz-Bayesian criterion) and HQC (Hannan-Quinn criterion) [27,34]. Information criterion (AIC) is a fined procedure created on in-sample fit to estimate the likelihood of a model to predict/estimate the future values. A good quality model is the one that has the lowest AIC among all the other models. The Bayesian information criterion (BIC) [35] is an alternative criterion for model choice that measures the trade-off among model fit and complexity of the model. A lower BIC value indicates a better fit. The following equations are used to estimate the AIC and BIC [34-36] of a model:

$$
\begin{gathered}
\text { AIC }=-2 \times \ln L+2 \times k \\
\text { BIC }=-2 \times \ln L+2 \times \ln N \times k
\end{gathered}
$$

where $\mathrm{L}$ is the amount of the likelihood, $\mathrm{N}$ is the number of recorded measurements, and $\mathrm{k}$ is the number of estimated parameters. 
The Hannan-Quinn information criterion (HQC) is a rate of the goodness of fit of a statistical model, and is regularly used as a criterion for model choice among a finite set of models. It is not constructed on log-likelihood function (LLF), but related to the information criterion of Akaike. Similar to AIC, the HQC introduces a penalty term for the number of factors in the model, but the penalty is larger than one in the AIC. In general, the BIC is defined as:

$$
\mathrm{HQC}=\mathrm{n} \times \ln \frac{\mathrm{RSS}}{\mathrm{n}}+2 \times \mathrm{k} \times \ln (\ln \mathrm{n})
$$

where:

- $\mathrm{n}$ is the amount of observations;

- $\mathrm{k}$ is the amount of model parameters;

- $\quad$ RSS is the residual sum of squares that result from the statistical model.

Given two estimated models, the model with the lower value of HQC is chosen; a lower HQC means either fewer explanatory variables improved fit, or both.

\subsection{Autocorrelation and Partially Autocorrelation Tests}

The tests of autocorrelation function (ACF) and partial autocorrelation function (PACF) are aimed for independent variables. In the first function, at lag $k$, there is a correlation between the series values that are k intervals apart. In the second case, at lag k, it is the correlation between the series values divided by $\mathrm{k}$ intervals from each other, with simultaneous recording of values in the intervals between them [27].

\subsection{Cointegration}

There is a rule that two non-stationary series show cointegration if the linear combination of these series is a stationary process. In particular, two series $X, Y$ are cointegrated if there are such $\alpha$ and $\beta$ that the series:

$$
Z=\alpha \times X-\beta \times Y
$$

is stationary. The variable $\mathrm{Z}$ is therefore a series of deviations from the long-term equilibrium state. The expected value of this variable defines the average in the long term, which is the relationship between the variables $X$ and $Y$. The coefficients $\alpha$ and $\beta$ determine the so-called cointegration vector. In the case of two series, there is at most one such vector. While generalizing to the case of more series, the time series are cointegrated if there is at least one cointegration vector such that the linear combination of the series is stationary [28].

The two most common approaches to test cointegration are the Engle-Granger method and the Johansen approach. The first method includes:

1. Stationary examination of variables with ADF test (Augmanted Dickey Fuler-test). All variables must be non-stationary;

2. Estimating the cointegration vector:

$$
y_{t}=x_{t} \beta+u_{t}
$$

3. If the rest of the model $u_{t}$ are stationary, then there is cointegration between the variables $x$ and $y$.

\section{ADF Test}

In statistics and econometrics, an augmented Dickey-Fuller test (ADF) examines the zero hypothesis that a unit root is current in a time series sample. The alternative hypothesis is different varying on which version of the test is used, but is typically stationary or trendstationary. It is an augmented version of the Dickey-Fuller test for a bigger and more difficult set of time series models. 
In the regression equation on the right, the lagged values of the dependent variable are plotted. The equation has the form:

$$
\Delta \mathrm{y}_{\mathrm{t}}=\alpha+\beta_{\mathrm{t}}+\delta \mathrm{y}_{\mathrm{t}-1}+\sum_{\mathrm{i}=1}^{\mathrm{k}} \gamma_{\mathrm{i}} \Delta \mathrm{y}_{\mathrm{t}-1}+\varepsilon_{\mathrm{t}}
$$

where $\alpha$ is the constant and $\beta$ is the coefficient for the variable representing time. Assuming that $\alpha$ and $\beta$ are equal to 0 we get a model related to random walk, and assuming that $\beta=0$ we get a model corresponding to random walk with a drift.

The null hypothesis in this test assumes that the process has a unit root and therefore it is non-stationary. The alternative hypothesis is that the process has no unit root and so it is stationary.

\section{Collecting Data and Statistical Analysis}

In order to do an analysis, the following groups of data for the years 2000-2019 (for each year) were collected and grouped:

Group A. Total investment outlays (NIO); investment outlays for fixed assets: total (NST), and broken down into buildings and structures (NBB), machinery (NM) and means of transport (NSS); value of fixed assets: net (WNST) and gross (WBST); depreciation level of fixed assets (SZST), gross value of fixed assets obtained from investments (WBSTI) [37]. All variables, except SZST, are in PLN. The variable SZST is in percentage points.

Group B. Level of investments of non-financial enterprises, employees more than 10 people and keep accounting books, from the energy sector: total (IOE), and broken down into small enterprises - up to 49 employees (IME) and medium and large enterprises, over 49 employees (ISiDE), for the years 2005-2019 [38]. All variables are in PLN.

Group C. Macroeconomic indicators for the energy sector: gross domestic product $(\mathrm{GDP})$, total output (PG), intermediate consumption $(\mathrm{ZP})$, number of employees $(\mathrm{P})$, costs associated with employment (KZ), taxes paid by producers (PP), subsidies to producers (DP), gross operating surplus (NOB) [38].

All variables, except $\mathrm{P}$, are in PLN. The variable $\mathrm{P}$ is in number of people.

Group D. Household consumption-home use and energy carriers: total (SD), and per capita (Sd1) [37]; and public consumption (SP) [39]. All variables are in PLN.

Group E. Interest rates of loans to non-financial enterprises: total (KO), up to 1 year (K1), from 1 to 5 years (K1_5), over 5 years (K5) [4]. All variables are in percentage points.

First, we conducted the canonical analysis. The number of cases must be higher than the number of variables minus 2. Therefore, the analysis was limited to 17 variables: 9 from Group A and 8 from Group C. The results of the analysis are presented in Table 1.

Table 1. Summary of the canonical analysis.

\begin{tabular}{|c|c|c|}
\hline \multirow[t]{2}{*}{$\mathbf{N}=20$} & \multicolumn{2}{|c|}{$\begin{array}{c}\text { Canonical R: } 0.99708 \\
\text { Chi }^{2}(72)=119.43 \\
p=0.00039\end{array}$} \\
\hline & Group A-Left & Group C-Right \\
\hline Number of variables & 9 & 8 \\
\hline Extracted variance & $99.1134 \%$ & $100.000 \%$ \\
\hline Total redundancy & $90.6513 \%$ & $91.4633 \%$ \\
\hline
\end{tabular}

Source: Authors' study.

The extracted variance and total redundancy indicate a high correlation between the two groups of variables. The first gauge shows the average amount of variance extracted from the variables in the relevant group by all canonical variables. Total redundancy, on the other hand, is the sum of redundancy for all canonical variables. This indicator can be interpreted as the average percentage of the variance explained in one group of variables for a given second group, based on all canonical variables. The results from Table 1 show 
that the left group explains $91.6 \%$ of the variability of the right group, while the right group explains $90.5 \%$ of the variability of the left group. Therefore, it suggests there is a relationship between investments in the energy sector and the macroeconomic components of national accounts generated by this industry.

In the next stage of the analysis we checked the stationarity of all 27 variables with the KPSS test (Kwiatkowski, Phillips, Schmidt and Shin). The test gave different results, depending on the selection of initial assumptions. However, most of the time series were non-stationary. Therefore, we calculated the first differences of the variables (denoted by the prefix " $\mathrm{d}$ "). They proved to be stationary. It also results from the drawings illustrating mew variables (Appendix A, Figures A1 and A2). On this basis further calculations were conducted.

In the next phase we calculated linear correlation coefficients of Pearson between potential explained and explanatory variables. The first set consisted of 12 potential dependent variables representing a level of investment of enterprises from the energy sector, Group A and B. The second set included the remaining 15 potential independent variables-Groups C, D and E. Table 2 shows the correlation coefficients considered at a significant level $p=0.05$.

Table 2. Significant correlation coefficients between the variables.

\begin{tabular}{ccccccccc}
\hline Variable & d_PG & d_ZP & d_KZ & d_SP & d_K1 & d_K1_5 & d_K5 & d_KO \\
\hline d_IME & & & 0.560486 & 0.533543 & 0.757241 & 0.734336 & 0.661062 & 0.716984 \\
\hline d_NIO & 0.546799 & 0.532638 & - & - & - & - & - & - \\
\hline d_NST & 0.543874 & 0.524437 & - & - & - & & - & - \\
\hline d_NM & 0.596575 & 0.575515 & - & - & - & - & - & - \\
\hline d_WBSTI & 0.490708 & - & - & - & - & - & - & - \\
\hline Source: Authors' study. & & & & & & &
\end{tabular}

There are many correlations between investments of small enterprises and the various interest rates. Although 13 coefficients are significant altogether, the correlation does not mean the actual relationship between the variables. In connection to the above, we conducted a study by causality of Granger. The calculations were completed with the Gretl program created on the vector autoregression models (VAR). The maximum possible order of the variable delay was set at 5 because of the relatively short time series. Furthermore, the selection of the delay order for a particular model was based on the criteria of AIC (Akaike criterion), BIC (Schwartz-Bayesian criterion) and HQC (Hannan-Quinn criterion).

There were 6 out of 13 coefficients that proved to be the causal correlations (for $p=0.1$ ). In two cases a causal relationship was reversed-the variable taken as originally dependent proved to be an explanatory variable for the one originally adopted for independent. There were no reciprocal relationships. There was also no causal link between changes in the level of investment in the energy sector and changes in interest rates for corporate loans offered by commercial banks. Table 3 shows the results of the calculations.

Based on the result of the Granger correlation, the following conclusions can be drawn:

- Changes of total investments of enterprises from the energy sector (d_NIO) are caused by an intermediate consumption (d_ZP) two years ago and total output (d_PG) in the energy sector five years ago;

- Changes in the investments for fixed assets in the energy sector enterprises (d_NST) are caused by the changes of total output in the energy sector (d_PG) five years ago;

- Changes in the investments in machines in the energy sector enterprises (d_NM) are caused by the changes of total output in the energy sector (d_PG) a year ago;

- Despite high correlation coefficients (above 0.9) between the variables d_NIO, d_NST and d_NM, they do not depend on the same factors; 
- Changes in the total output in the energy sector (d_PG) are caused by changes in the gross value of fixed assets obtained from investments by energy sector enterprises (d_WBSTI) up to four years back;

- Changes in the level of intermediate consumption in the energy sector $\left(\mathrm{d} \_\mathrm{ZP}\right)$ are caused by changes in the level of investment in machines in energy sector enterprises (d_NM) up to four years back;

- The signs of correlation coefficients (Table 2) suggest that all of the above-mentioned dependencies are simply proportional (positive).

Table 3. Causal correlations-the $p$-value, and essential government delays.

\begin{tabular}{ccc}
\hline \multirow{2}{*}{$\begin{array}{c}\text { Explained } \\
\text { variable }\end{array}$} & \multicolumn{2}{c}{ Explanatory variables } \\
\cline { 2 - 3 } d_NIO & d_ZP & d_PG \\
\hline d_NST & 0.0891 VAR $(2)$ & 0.0640 VAR (1.3.5) \\
\hline d_NM & - & 0.1004 VAR (1.3.5) \\
\hline $\begin{array}{c}\text { Explained } \\
\text { variable }\end{array}$ & \multicolumn{2}{c}{ Explanatory variables } \\
\hline d_PG & \multicolumn{2}{c}{ d_WBSTI } \\
\hline \multirow{2}{c}{0.0744 VAR (4) } \\
\hline d_ZP & \multicolumn{2}{c}{ d_NM } \\
\hline \multicolumn{2}{c}{0.0778 VAR (4) } \\
\hline
\end{tabular}

Source: Authors' study.

Additionally, the autocorrelation (ACF) and partial autocorrelation (PACF) functions for the dependent variables (groups A and B) were examined. In a few cases there is negative autocorrelation and/or partial autocorrelation. The results are presented in Table 4.

Table 4. Autocorrelations and partial autocorrelations of variables.

\begin{tabular}{cccc}
\hline Variable & ACF Delay & PACF Delay & Significance Level \\
\hline d_ISiDE & & 2 years & 0.10 \\
\hline d_NBB & 2 years & 2 years & 0.10 \\
\hline
\end{tabular}

Source: Authors' study.

The results show that the current changes in the level of investments in medium and large companies in the energy sector and investments in buildings in the energy sector are influenced by their values from two years ago. In addition, we conducted an analysis of cointegration in selected pairs of variables. Their first differences showed a causal relationship. The analysis was not performed for all possible combinations of pairs of variables (one variable from group $\mathrm{A}$ or $\mathrm{B}$ and the other variable from group $\mathrm{C}, \mathrm{D}$ or $\mathrm{E}$ ) as this would require the estimation of 180 models. This analysis was aimed at detecting, without determining causality, other relationships between variables over a long period of time. The results are shown in Table 5. The terms "dependent variable" and "independent variable" in this case refer to the order of the variables in the cointegrating equation. Models without the intercept ranging from no delay to a delay of 5 years were tested. The AIC criterion was chosen for selecting the order of delay. 
Table 5. The asymptotic $p$ values for the residuals of the cointegration equation.

\begin{tabular}{ccc}
\hline \multirow{2}{*}{$\begin{array}{c}\text { Dependent } \\
\text { Variable }\end{array}$} & ZP & Independent Variable \\
\cline { 2 - 3 } NIO & 0.14 & 0,6694 \\
\hline NST & 0.6887 \\
\hline NM & 0.522 \\
\hline $\begin{array}{c}\text { Dependent } \\
\text { variable }\end{array}$ & Independent variable \\
\hline PG & WBSTI \\
\hline ZP & 0.3726 \\
\hline
\end{tabular}

Source: Authors' study.

As shown in Table 5, no cointegration was found. Although the variables are nonstationary, as demonstrated by both the ADF test used in this analysis and the KPSS test used earlier, the residuals from the cointegrative equations are also non-stationary.

\section{Discussion and Conclusions}

The goal of the paper was to analyze the determinants of investments made by enterprises from the energy sector as well as their delays in Poland in the years 2000-2019. Therefore, the study is the basis for a scientific discussion in the area of research about determinants of investment decisions by enterprises in the energy sector in Poland. The discussion is mainly driven by the verification of four research hypotheses:

Hypothesis 1 (H1). Changes in the value of macroeconomic indicators have a positive impact on changes in investment spending by companies from the energy sector in Poland.

The hypothesis was confirmed in the case of intermediate consumption and total output. Since intermediate consumption and total output are important components of economic growth [38], the results confirm the positive linkage of economic growth measures with energy investments [14]. The results further enhance the previous findings as these factors also influence investments for fixed assets and machines. However, the delay of the impact varies from one to five years. Furthermore, there is a relationship in the opposite direction, too. Gross value of fixed assets as well as investments in machines influence the total output and intermediate consumption in the energy sector.

Hypothesis 2 (H2). Changes in the value of consumption have a positive impact on changes in investment spending by companies from the energy sector in Poland.

The results are inconclusive. There is only a correlation of Pearson between public consumption and investments by small enterprises. However, this relationship is rather average and is not confirmed by the causality correlation.

Hypothesis 3 (H3). Changes in the value of interest rates have a negative impact on changes in investment spending by companies from the energy sector in Poland.

The results are inconclusive. There are significant correlations of Pearson between investments of small enterprises and the interest rates of all types of loans. However, these relationships are not confirmed by casual correlation. This confirms that financial constraints due to capital costs for investments have a negative effect on investment activity [2,3]. Moreover, the findings suggest higher sensitivity of small firms to changes 
in the cost of capital and the challenges these firms face in managing the interest rate risk [28]. This is further intensified by poor development of financial and legal institutions in Poland [29].

Hypothesis 4 (H4). Changes in the value of past investments have a negative impact on changes in current investment spending by companies from the energy sector in Poland.

The hypothesis was confirmed, but for medium and large-sized enterprises. In the case of all companies, the positive confirmation regards investments in buildings. Moreover, the delay was estimated for two years. This is consistent with the theory that when companies have already invested they have enough capacity and do not need new investments in the nearest future. Therefore, this is fully consistent with previous research that indicates that investments depend negatively on production capacity and past investment engagement, especially in medium and large enterprises [1,27].

Research results are consistent with classical theoretical assumptions, in which the most significant determinants are related to energy sector conditions, government policies, market opportunities, and economic and business conditions [25]. However, the results indicate that investments in the energy sector in Poland are characterized by certain specifics that are rather typical for developing economies than for already developed and well-industrialized markets [26]. An important contribution of the article is also to highlight the differences in the determinants in investments of energy companies of different sizes [27]. This is important both in terms of understanding the barriers to investment due to the scale of operations, as well as public programs to support the development of small and medium-sized energy enterprises [28]. The results are also closely linked to an inconclusive assessment of the macroeconomic condition of the Polish economy in the years 2000-2019. Different socio-economic conditions and the impact of multiple economic shocks [29] have been a source of risk and a cause of policy uncertainty, which is a powerful deterrent to immediate investments in the energy sector [40].

Therefore, the main scientific contribution of the paper is to provide significant cognitive value to undertaking and planning the course of investment processes, as well as designing policies and programs [31] for the improvement of efficiency in Polish companies in the energy sector. However, when considering the obtained results, the limitations of the research should be taken into account [32]. They mainly include a limited geographical scope of considerations restricted to Poland. For this reason, the conclusions are characterized by limited generalizability but can be successfully used, for example, in understanding and enhancing investment decisions in the energy sector in other developing countries.

The research results obtained also allow formulation of the following practical implications:

- In order to increase the effectiveness of investment decisions in the energy sector in Poland, managers should conduct anticipatory analyses, taking into account trends and prospects for economic growth, with particular reference to such macroeconomic indicators as intermediate consumption and total output;

- Due to the increased sensitivity of investments of small energy companies in Poland to changes in public consumption and interest rates, entrepreneurs and managers in these entities should develop methods of financial and relationship risk management. It will be particularly important to use appropriate insurance products and adequate protection of interests through economic contracts;

- An effective way of improving small energy firms' access to stable, reliable and secure external financing appears to be through institutional reforms addressing weaknesses in the legal and financial systems in Poland;

- Managers of medium and large energy companies in Poland should take a long-term (strategic) perspective in their planning process to ensure the ability of companies to generate the resources necessary to invest in next-generation projects; 
- Policies and programs for the development of energy enterprises in Poland should be adjusted to the needs of companies of different sizes to encourage continuous investment and be consistent with an appropriate macroeconomic policy aimed at long-term economic growth.

The importance of determinants of investments in the energy sector in Poland indicates the need for the continuation of research. Prospective future research directions should be focused on identification and evaluation of changes in investment factors during the COVID-19 pandemic (2020-2021 and later). Moreover, these analyses can be carried out at different levels: dyads and triads, networks, and ecosystems of enterprises and their stakeholders. From the meso- and macroeconomic point of view, the analyses of the determinants of investments in the energy sector in Poland related to the socio-economic development of the regions and country will be interesting both for academics and politicians.

Author Contributions: Conceptualization, M.W. and R.L.; methodology, R.L.; validation, R.L., M.W. and M.M.; formal analysis, R.L.; writing—original draft preparation, R.L., M.W., P.J., S.K. and M.M.; writing - review and editing, M.W., S.K. and M.M. All authors have read and agreed to the published version of the manuscript.

Funding: This research was funded by the AGH University of Science and Technology in Kraków (institutional subsidy for maintaining the research capacity).

Institutional Review Board Statement: Not applicable.

Informed Consent Statement: Not applicable.

Data Availability Statement: Not applicable.

Conflicts of Interest: The authors declare no conflict of interest.

Appendix A
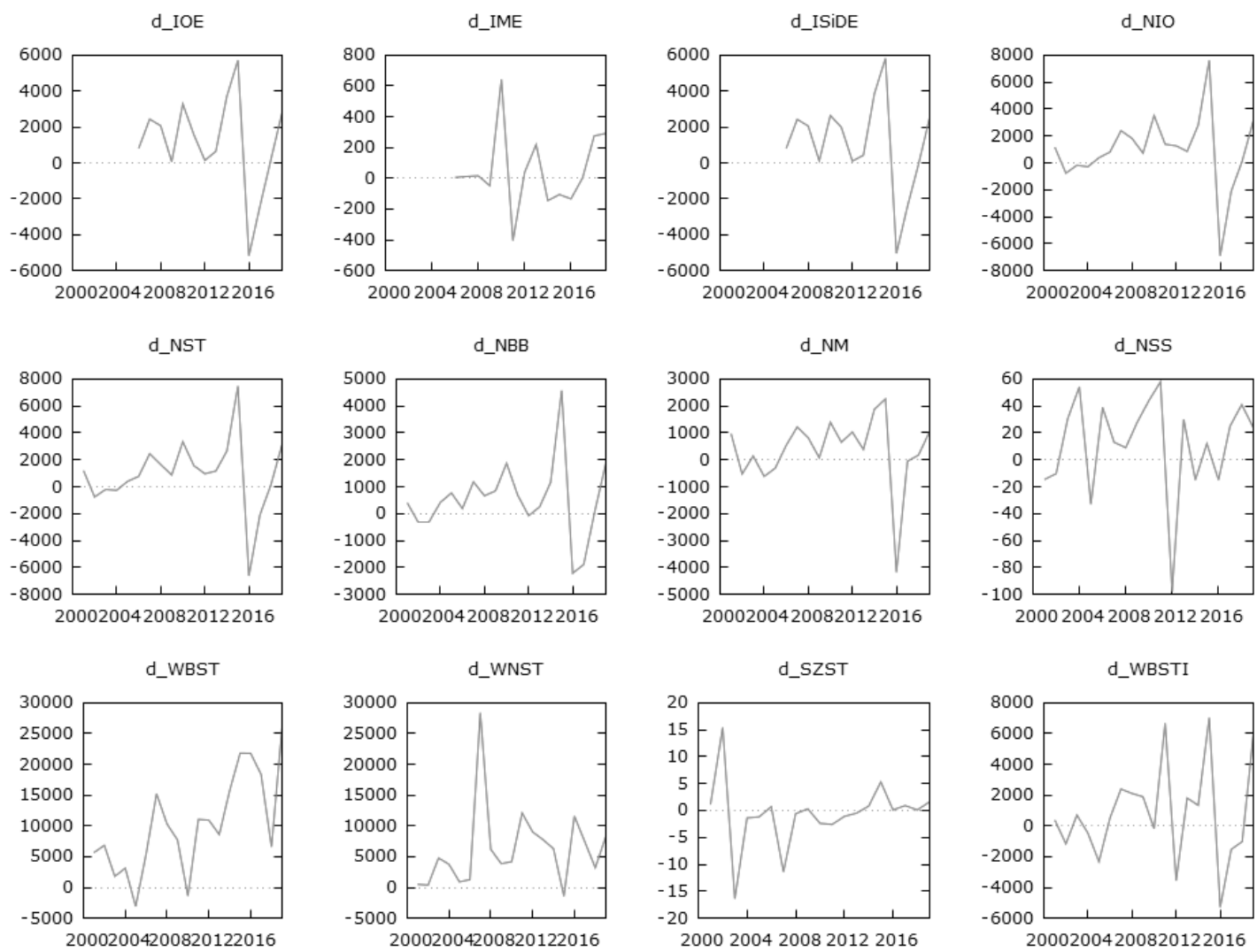

Figure A1. Stationary variables from Groups A and B. Source: Authors' study. 
d_PKB

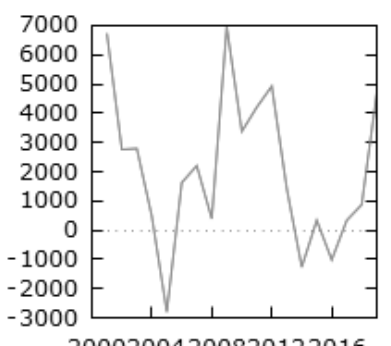

d_KZ

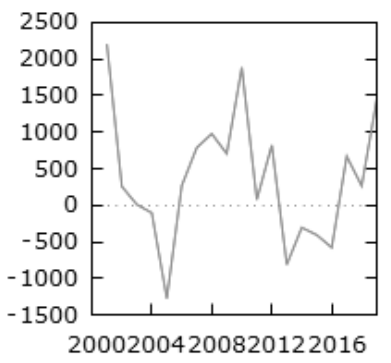

d_SD

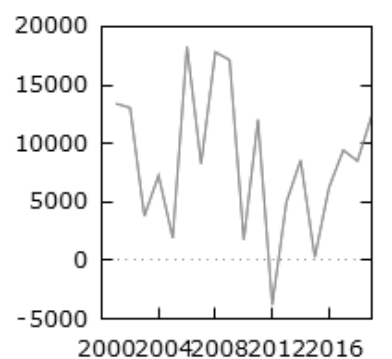

d_K15

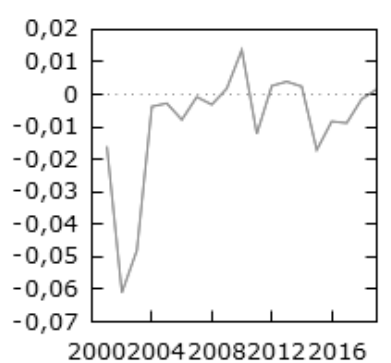

d_PG

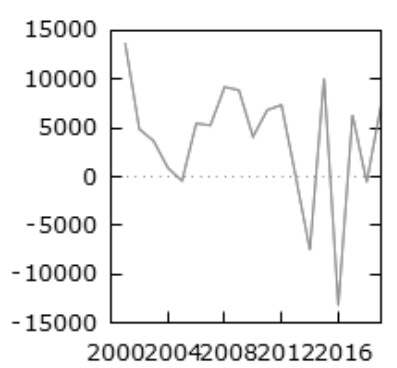

d_PP

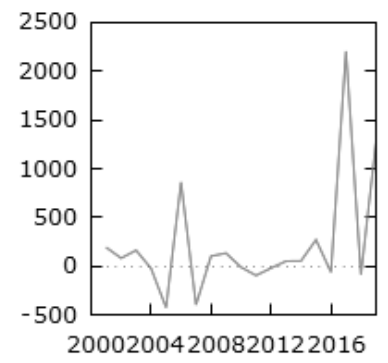

d_SD1

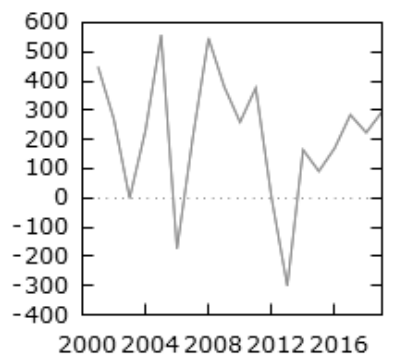

d_K5

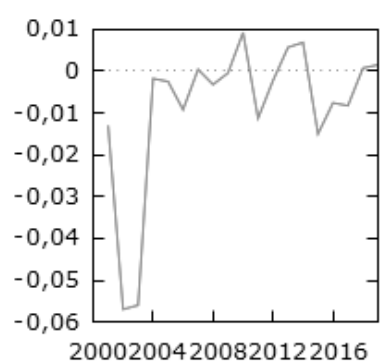

d_ZP

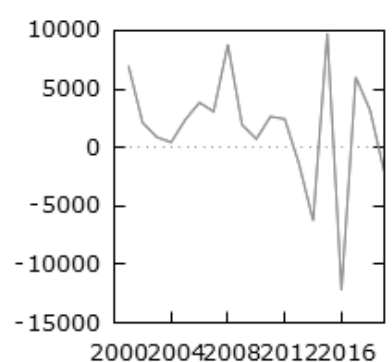

d_DP

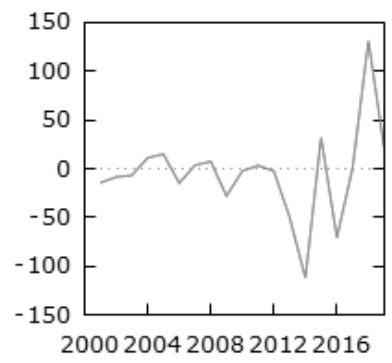

d_SP

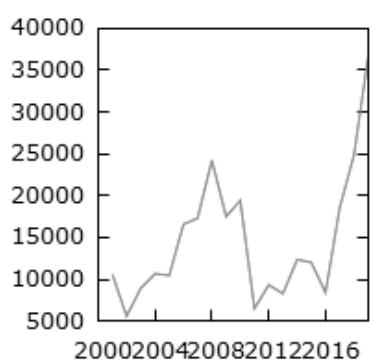

d_KO

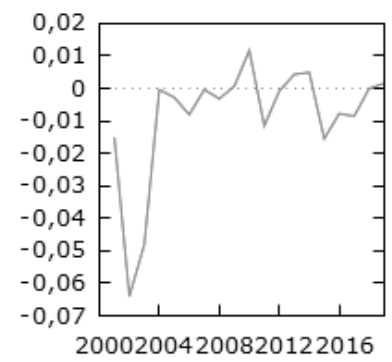

d_P

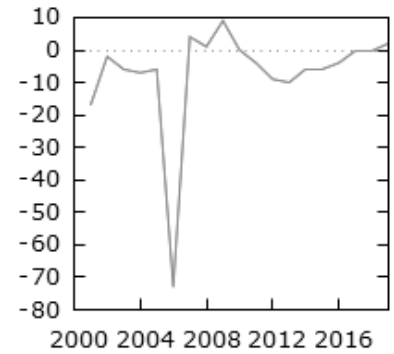

d_NOB

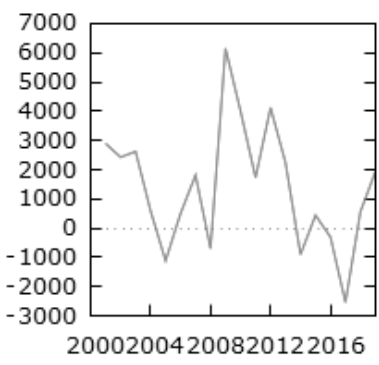

d_K1

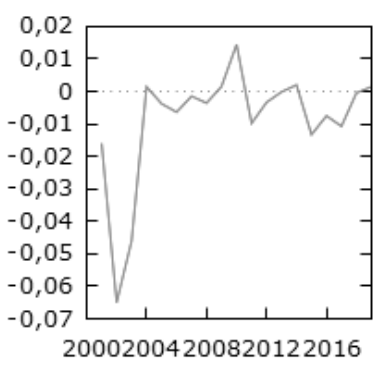

20002004200820122016

Figure A2. Stationary variables from groups C, D and E. Source: Authors' study.

\section{References}

1. European Union. EU Energy in Figures Statistical Pocketbook; Directorate-General for Energy, European Commission: Brussels, Belgium, 2019.

2. Sharma, N.; Smeets, B.; Tryggestad, C. The Decoupling of GDP and Energy Growth: A CEO Guide; McKinsey: New York, NY, USA, 2019; pp. 1-13.

3. European Statistical Office, Eurostat (online data code: Prc_ppp_ind). Available online: https://ec.europa.eu/eurostat (accessed on 25 May 2021).

4. Carraro, C.; Favero, A.; Massetti, E. Investments and public finance in a green, low carbon, economy. Energy Econ. 2012, 34, S15-S28. [CrossRef]

5. Armeanu, D.Ş.; Vintilă, G.; Gherghina, Ş.C. Does Renewable Energy Drive Sustainable Economic Growth? Multivariate Panel Data Evidence for EU-28 Countries. Energies 2017, 10, 381. [CrossRef]

6. Soava, G.; Mehedintu, A.; Sterpu, M.; Raduteanu, M. Impact of renewable energy consumption on economic growth: Evidence from European Union countries. Technol. Econ. Dev. Econ. 2018, 24, 914-932. [CrossRef] 
7. Hanif, I. Impact of economic growth, nonrenewable and renewable energy consumption, and urbanization on carbon emissions in Sub-Saharan Africa. Environ. Sci. Pollut. Res. 2018, 25, 15057-15067. [CrossRef] [PubMed]

8. Asiedu, B.A.; Hassan, A.A.; Bein, M.A. Renewable energy, non-renewable energy, and economic growth: Evidence from 26 European countries. Environ. Sci. Pollut. Res. 2021, 28, 11119-11128. [CrossRef] [PubMed]

9. Grijó, T.; Soares, I. Solar photovoltaic investments and economic growth in EU: Are we able to evaluate the nexus? Environ. Dev. Sustain. 2016, 18, 1415-1432. [CrossRef]

10. Gródek-Szostak, Z.; Suder, M.; Kusa, R.; Szelag-Sikora, A.; Duda, J.; Niemiec, M. Renewable Energy Promotion Instruments Used by Innovation Brokers in a Technology Transfer Network. Case Study of the Enterprise Europe Network. Energies 2020, $13,5752$. [CrossRef]

11. Krugman, P.; Wells, R. Macroeconomics, 4th ed.; Worth Publishers: Warszawa, Poland, 2015.

12. Kasahara, T. Severity of financing constraints and firms' investments. Rev. Financ. Econ. 2008, 17, 112-129. [CrossRef]

13. Zubair, S.; Kabir, R.; Huang, X. Does the financial crisis change the effect of financing on investment? Evidence from private SMEs. J. Bus. Res. 2020, 110, 456-463. [CrossRef]

14. Akbar, S.; Rehman, S.U.; Ormrod, P. The impact of recent financial shocks on the financing and investment policies of UK private firms. Int. Rev. Financ. Anal. 2013, 26, 59-70. [CrossRef]

15. Balduzzi, P.; Brancatib, E.; Schiantarellic, F. Financial markets, banks' cost of funding, and firms' decisions: Lessons from two crises. J. Financ. Intermediat. 2018, 36, 1-15. [CrossRef]

16. Vermoesen, V.; De Loof, M.; Laveren, E. Long-term debt maturity and financing constraints of SMEs during the Global Financial Crisis. Small Bus. Econ. 2013, 41, 433-448. [CrossRef]

17. Farina, L.; Prego, P. Investment Decisions and Financial Standing of Portuguese Firms—Recent Evidence, Financial Stability Report; Banco de Portugal: Lisboa, Portugal, 2013; pp. 105-125.

18. Perić, M.; Đurkin, J. Determinants of investment decisions in a crisis: Perspective of Croatian small firms. Management 2015, 20, 115-133.

19. Giebel, M.; Kraft, K. The impact of the financial crisis on capital investments in innovative firms. Ind. Corp. Chang. 2018, 28, 1-24. [CrossRef]

20. Laperche, B.; Lefebvre, G.; Langlet, D. Innovation strategies of industrial groups in the global crisis: Rationalization and new paths. Technol. Forecast. Soc. Chang. 2011, 78, 1319-1331. [CrossRef]

21. Archibugi, D.; Filippetti, A.; Frenz, M. The impact of the economic crisis on innovation: Evidence from Europe. Technol. Forecast. Soc. Chang. 2013, 80, 1247-1260. [CrossRef]

22. Karafolas, S.; Ragias, V. Economic crisis effects on investment plans: The case of the LEADER program in the region of West Macedonia, Greece. In Proceedings of the 13th International Conference of "Economies of the Balkan and Eastern European Countries", EBEEC 2021, Pafos, Cyprus, 14-16 May 2021.

23. Ministerstwo Energii. Polityka Państwa do Roku 2040; Ministerstwo Energii: Warszawa, Poland, 2018.

24. Główny Urząd Statystyczny. 2020. Available online: https://stat.gov.pl (accessed on 25 May 2021).

25. Sultan, Z.A.; Haque, M.I. The estimation of the cointegration relationship between growth, domestic investment and exports: The Indian economy. Int. J. Econ. Financ. 2011, 3, 226-232. [CrossRef]

26. Inessa, S.; Artem, S.; Wielki, J. Analysis of Macroeconomic Factors Affecting the Investment Potential of an Enterprise. Eur. Res. Stud. J. 2019, XXII, 140-167. [CrossRef]

27. Wozniak, M.; Lisowski, R.; Dudek, M. Relationships between Macroeconomics Indicators and Investments of Enterprises: Evidence from Poland. Eur. Res. Stud. J. 2021, XXIV, 555-567. [CrossRef]

28. Harris, R.J. The invalidity of partitioned U tests in canonical correlation and multivariate analysis of variance. Multivar. Behav. Res. 1976, 11, 353-365. [CrossRef]

29. Barcikowski, R.; Stevens, J.P. A Monte Carlo study of the stability of canonical correlations, canonical weights, and canonical variate-variable correlations. Multivar. Behav. Res. 1975, 10, 353-364. [CrossRef] [PubMed]

30. Engle, R.F.; Granger, C.W.J. (Eds.) Long-Run Economic Relationships; Oxford University Press: Oxford, UK, 1992.

31. Charemza, W.W.; Deadman, D.F. Nowa Ekonometria; PWE: Warszawa, Poland, 1997.

32. Osińska, M. Ekonometria Wspótczesna; TNOiK Dom Organizatora: Torun, Poland, 2007.

33. Aaker, D.A.; Kumar, V.; Leone, P.R.; Day, S.G. Marketing Research, 11th ed.; John Wiley \& Sons: Hoboken, NJ, USA, 2013.

34. Akaike, H. A new look at the statistical model identification. IEEE Trans. Autom. Control 1974, 19, 716-723. [CrossRef]

35. Stone, M. Comments on Model Selection Criteria of Akaike and Schwarz. J. R. Stat. Soc. Ser. B 1979, 41, 276-278. [CrossRef]

36. Lisowski, R.; Woźniak, M.; Wójtowicz, T. Impact of Fiscal Instruments on Investments of Industrial Enterprises in Poland W: Functioning and Development of Enterprises: Contemporary Challenges; Duda, J., Skalna, I., Eds.; Wydawnictwa AGH: Kraków, Poland, 2019; pp. 63-69.

37. Główny Urząd Statystyczny, Rocznik Statystyczny Rzeczypospolitej Polskiej 2001-2020, Zakład Wydawnictw Statystycznych, Warszawa, 2001-2020. Available online: https:/ /stat.gov.pl/obszary-tematyczne/roczniki-statystyczne/roczniki-statystyczne/ rocznik-statystyczny-rzeczypospolitej-polskiej-2020,2,20.html (accessed on 25 May 2021). 
38. Główny Urząd Statystyczny, Wyniki Finansowe Przedsiębiorstw Niefinansowych, Zakład Wydawnictw Statystycznych, Warszawa, 2006-2019. Available online: https://stat.gov.pl/obszary-tematyczne/podmioty-gospodarcze-wyniki-finansowe/ przedsiebiorstwa-niefinansowe/wyniki-finansowe-przedsiebiorstw-niefinansowych-i-vi-2020,11,23.html (accessed on 9 October 2020).

39. Główny Urząd Statystyczny. Available online: https:/ / stat.gov.pl/wskazniki-makroekonomiczne/ (accessed on 26 May 2021).

40. Narodowy Bank Polski. Available online: https://www.nbp.pl/home.aspx?f=/statystyka/pieniezna_i_bankowa/oprocentowanie.html (accessed on 25 May 2021). 